\title{
Bacterial contamination of the hands of intensive care unit staff during respiratory tract care: preliminary results
}

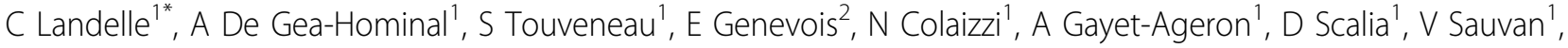 \\ J Schrenzel ${ }^{3}$, P Francois ${ }^{3}$, J Pugin $^{2}$, D Pittet ${ }^{1}$
}

From 3rd International Conference on Prevention and Infection Control (ICPIC 2015)

Geneva, Switzerland. 16-19 June 2015

\section{Introduction}

Optimal care of the respiratory tract (RT) is critical to prevent ventilator-associated pneumonia in ICU. The dynamics of microbial cross-transmission by the hands of health care workers $(\mathrm{HCW})$ during $\mathrm{RT}$ care is currently unknown.

\section{Objectives}

To study the level of HCWs' hand contamination during RT care.

\section{Methods}

Structured observations of RT care sequences were conducted by trained external observers. At the beginning and the end of each care sequence observed, imprints of the 5 fingertips of the dominant hand, with and without gloves, were taken on blood agar plates. Bacterial colony-forming units (CFUs) were quantified after $18 \mathrm{hrs}$ of incubation at $35^{\circ} \mathrm{C}$. The primary outcome was the number of $\mathrm{CFU} /$ plate at the end of the care sequence and before performing hand hygiene, expressed as medians and interquartile range.

\section{Results}

A total of 207 structured observations were performed: nasal care $(\mathrm{n}=31)$, nasal care with fixing of the nasogastric tube (NGT;n=31), oral care with water $(n=29)$, oral care with chlorhexidine ( $\mathrm{CHX} ; \mathrm{n}=50)$, fixing of respiratory tube $(n=33)$ and endo-tracheal aspiration $(n=33)$. Hand hygiene compliance before aseptic care was $70 \%$. Gloves were used for $94.2 \%$ of care sequences and a gloves'

${ }^{1}$ Infection Control Program, University of Geneva Hospitals, Geneva Switzerland

Full list of author information is available at the end of the article contamination $>10$ CFUs before care was observed in $24.2 \%$ of care sequences. When considering RT care activities with $\leq 10$ CFUs on hands or gloves at the start of care, we observed a median of 49 [6-88], 111 [37-277], 140 [50-317], 43 [14-168], 156 [15-308], and 4 [1-18] $\mathrm{CFU} /$ plates for nasal care $(\mathrm{n}=23)$, nasal care with fixing of the NGT $(n=21)$, oral care with water $(n=23)$, oral care with $\mathrm{CHX}(\mathrm{n}=33)$, fixing of the respiratory tube $(\mathrm{n}=21)$ and endo-tracheal aspiration $(n=26)$, respectively.

\section{Conclusion}

Among different types of RT care in intubated patients, fixing of the NGT or respiratory tube and oral care with water showed the higher levels of bacterial contamination. Oral care with CHX was associated with lower contamination levels than oral care with water. Further analyses will be conducted to model the dynamics of bacterial contamination according to the duration of care.

\section{Disclosure of interest}

None declared.

\begin{abstract}
Authors' details
'Infection Control Program, University of Geneva Hospitals, Geneva, Switzerland. ${ }^{2}$ Intensive Care Unit, University of Geneva Hospitals, Geneva, Switzerland. ${ }^{3}$ Genomic Research Laboratory, University of Geneva Hospitals, Geneva, Switzerland.
\end{abstract}

Published: 16 June 2015

doi:10.1186/2047-2994-4-S1-P246

Cite this article as: Landelle et al: Bacterial contamination of the hands of intensive care unit staff during respiratory tract care: preliminary results. Antimicrobial Resistance and Infection Control 2015 4(Suppl 1):P246. 